These pages offer you the chance to open topics for debate, discuss latest issues, or even offer advice to fellow readers. In this issue the Chief Executive of the GDC explains the change of name from PCD to DCP and Pam Swain from the BADN warns of problems over subscriptions and memberships. Send us your views on these issues or anything to do with working in the dental profession. We look forward to hearing from you.

\title{
PCD to DCP a DH decision on the DA explained by the CE of the GDC
}

Many of your readers may be wondering why the General Dental Council has started using the term 'dental care professional' in place of 'professional complementary to dentistry', seemingly without warning.

This new term originates with the Department of Health. Just before the changes to the Dentists Act were placed before the Westminster and Scottish Parliaments in the summer, the DH decided to change the term PCD to DCP - 'dental care professional'.

We decided that for consistency, and to avoid any possible confusion from the public, the GDC should use the term DCP from now on. I hope your readers will understand the reasons for the change.

This does not affect the professional groups' individual titles
- so a dental hygienist will still be known as a dental hygienist, and a dental nurse will still be known as a dental nurse.

Readers should also remember that once registration has become compulsory for all groups (two years after the new register opens), their DCP titles will be protected by law. This means that you will need to be registered with the GDC before you can use any of the DCP titles.

For the latest information on DCP registration, readers should visit the 'Potential registrant' section of our website at www. gdc-uk.org, or contact our DCP help-line (email dcp@gdc-uk.org or call 02073443740 ).

Antony Townsend

GDC Chief Executive and Registrar

\section{Subscription buyer beware - publication or membership - check carefully}

It has come to our attention that a number of dentists have been paying, on behalf of their dental nurses, for a subscription to a new dental nursing magazine under the misapprehension that this will entitle the dental nurses concerned to the benefits of BADN membership.

Whilst BADN is happy to provide this magazine with both articles and a representative to its Editorial Board, the Association has no commercial or financial connection with the magazine or its publishers, and does not in any way profit from the money paid in subscriptions. Taking out a $\mathfrak{E} 50$ annual subscription to this magazine does not, therefore, confer BADN membership with its accompanying benefits.

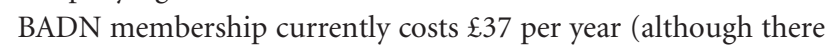
are lower rates for students, part-time workers, etc) and, in addition to our own quarterly British Dental Nurses' Journal, entitles dental nurse members to a wide range of benefits - including free legal advice; support, advice and information on a wide range of topics including Health \& Safety advice sheets; a free CD-Rom full of information, articles and advice; and discounts on a wide range of products and services - from home, car and travel insurance through holidays to high street items such as dvds and videos, as well as health care, eye care, fitness clubs, dental nurse textbooks and magazine packages for the waiting room. BADN also has a network of National and Local Groups which offer Continuing Professional Development through a series of Study Days available at discounted rates to BADN members. The membership fee is tax deductible.

Employers may obtain membership application forms by contacting BADN on 01253338360 or at admin@badn.org.uk

\section{Pamela Swain \\ Chief Executive, British Association of Dental Nurses}




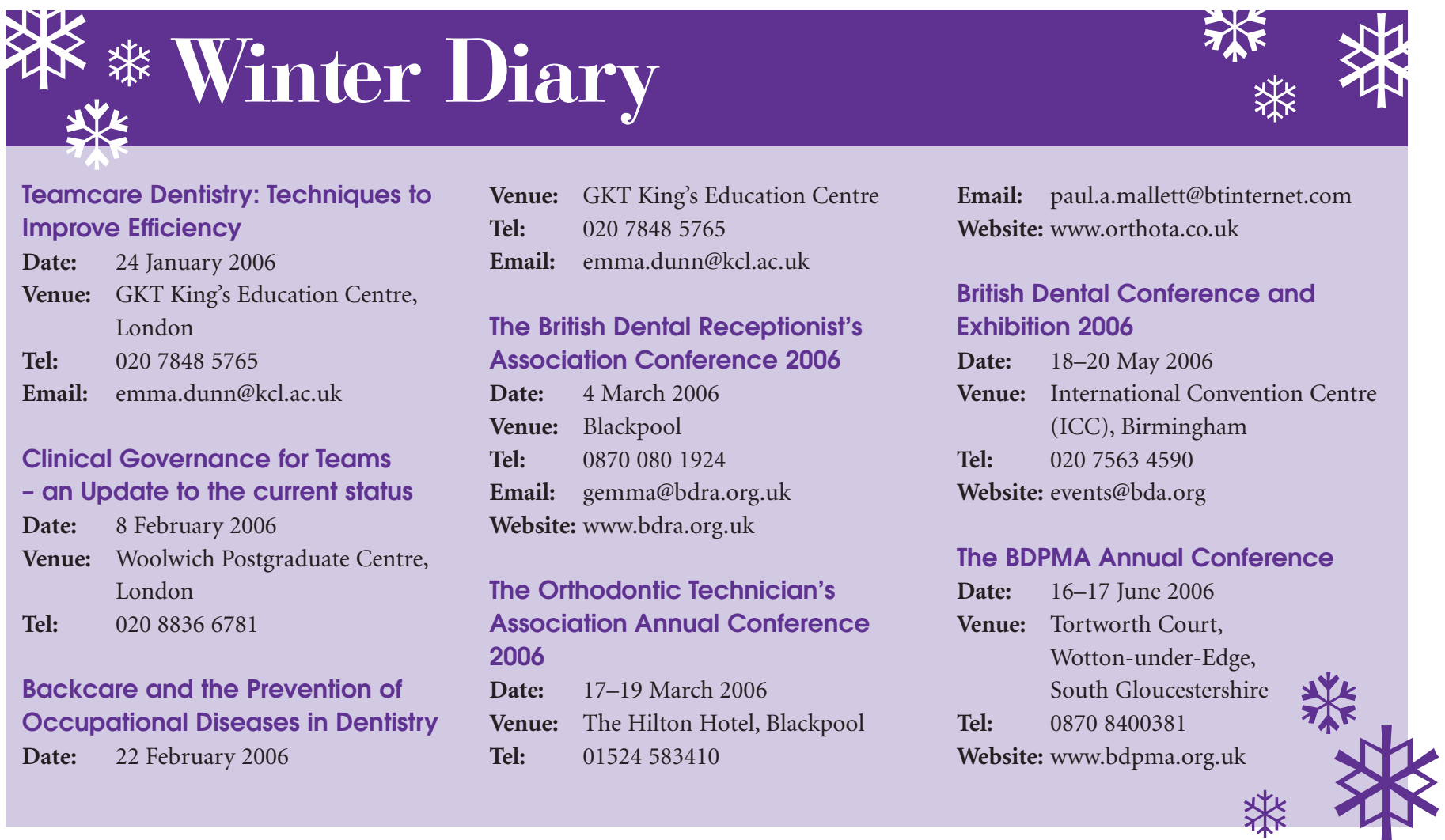

\section{Please SEND YOUR LETTERS,} which may be edited for reasons of space, to:

The Editor, Vital Magazine, BDJ, Nature Publishing Group, 4-6 Crinan Street,

London

NI 9XW

or email vitaleditorial@nature.com

Write to us for our Spring 2006 issue and you could be the lucky winner of our Star Letter writer competition.

Apart from the obvious glory you

will then receive a collection of the latest Colgate Oral Health Professional products ( $£ 100$ RRP) courtesy of Colgate.

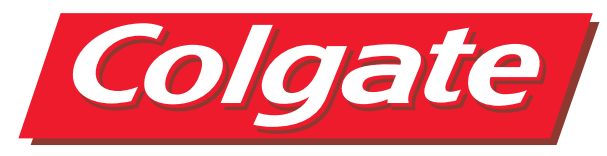

The Scientific Basis of Oral Health Education

The aim of this book is to provide a sound basis for giving information and advice on the main aspects of oral health. It gives a brief overview of the main oral diseases and some other oral conditions, together with four key messages. These

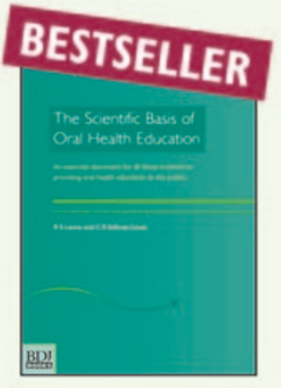
key messages are a consensus of expert opinion and should form the basis of all oral health advice given to the public.

As well as for members of the dental team, the book will be essential for dental undergraduate and postgraduate teaching and for those involved in general healthcare, such as medical practitioners, school nurses, health visitors, midwives, dietician and pharmacists.

- By R S Levine and C R Stillman-Lowe

- 75 pages

- ISBN $090458884 X$

- The more you order, the more you save! Buy in bulk today!

I copy $=£ 19.95$

2 or more copies $=\mathbf{f} \mathbf{1 7 . 9 5}$ (each copy)

5 or more copies $=\boldsymbol{£} \mathbf{1 4 . 9 5}$ (each copy)

10 or more copies $=€ \mathbf{9 . 9 5}$ (each copy) BOOKS 